\title{
Clinical outcomes of the Dynesys dynamic neutralization system: 1-year preliminary results
}

\author{
William C. Welch, M.D., ${ }^{1}$ Boyle C. Cheng, Ph.D., ${ }^{1}$ TariQ E. Awad, M.D. ${ }^{1,2}$ \\ Reginald Davis, M.D., ${ }^{3}$ JaMes H. MaXwell, M.D., ${ }^{4}$ RiCK Delamarter, M.D., ${ }^{5}$ \\ Jeffrey K. Wingate, M.D., ${ }^{6}$ John Sherman, M.D., ${ }^{7}$ ANd M. Mason Macenski, Ph.D. ${ }^{8}$ \\ ${ }^{1}$ University of Pittsburgh Medical Center-Health System, Presbyterian University Hospital, \\ Pittsburgh, Pennsylvania; ${ }^{2}$ Suez Canal University, Ismailia, Egypt; ${ }^{3}$ Greater Baltimore Medical \\ Center, Baltimore, Maryland; ${ }^{4}$ Scottsdale Spine Care, Scottsdale, Arizona; ${ }^{5}$ The Spine Institute, Santa \\ Monica, California; ${ }^{6}$ Michigan Spine Institute, Waterford, Michigan; ${ }^{7}$ Twin Cities Orthopaedic, \\ Minneapolis, Minnesota; and ${ }^{8}$ Zimmer Spine, Minneapolis, Minnesota
}

\begin{abstract}
Object. In this study the authors present the preliminary clinical outcomes of dynamic stabilization with the Dynesys spinal system as part of a multicenter randomized prospective Food and Drug Administration (FDA) investigational device exemption (IDE) clinical trial.

Methods. This study included 101 patients from six IDE sites (no participants were omitted from the analysis) who underwent dynamic stabilization of the lumbar spine with the Dynesys construct. Patient participation was based on the presence of degenerative spondylolisthesis or retrolisthesis (Grade I), lateral or central spinal stenosis, and their physician's determination that the patient required decompression and instrumented fusion for one or two contiguous spinal levels between L-1 and S-1. Participants were evaluated preoperatively, postoperatively at 3 weeks, and then at 3-, 6-, and 12-month intervals. The 100-mm visual analog scale was used to score both lowerlimb and back pain. Patient functioning was evaluated using the Oswestry Disability Index (ODI), and the participants' general health was assessed using the Short Form-12 questionnaire. Overall patient satisfaction was also reported.

One hundred one patients (53 women and 48 men) with a mean age of 56.3 years (range $27-79$ years) were included. The mean pain and function scores improved significantly from the baseline to 12-month follow-up evaluation, as follows: leg pain improved from 80.3 to 25.5 , back pain from 54 to 29.4, and ODI score from 55.6 to $26.3 \%$.

Conclusions. The early clinical outcomes of treatment with Dynesys are promising, with lessening of pain and disability found at follow-up review. Dynesys may be preferable to fusion for surgical treatment of degenerative spondylolisthesis and stenosis because it decreases back and leg pain while avoiding the relatively greater tissue destruction and the morbidity of donor site problems encountered in fusion. However, long-term follow-up care is still recommended.
\end{abstract}

\section{Key Words - degenerative disc disease - lumbar spine - dynamic stabilization - dynamic neutralization system $\bullet$ clinical trial}

$\mathrm{W}$ ITH the recent developments in fusion techniques, successful radiographically confirmed fusion rates have exceeded $95 \%$, but this has failed to correlate with a comparable increase in successful clinical outcomes, which are achieved in approximately $70 \%$ of cases. . 20,26 In several published studies investigators have questioned the efficacy of spinal fusion in the treatment of low-back pain. ${ }^{11}$ In addition, significant concerns have been raised related to adjacent-segment disease found in long-term patient follow-up review after spinal fusion. ${ }^{4,9,14,15}$ From a clinical point of view, the sacrifice of a moderately degenerated disc may not be desirable. In

Abbreviations used in this paper: $\mathrm{BMI}=$ body mass index; DDD = degenerative disc disease; IDE = investigational device exemption; $\mathrm{MCS}=$ Mental Component Summary; ODI = Oswestry Disability Index; PCS = Physical Component Summary; PET = polyethylene terephthalate; SF-12 = Short Form-12; VAS = visual analog scale. addition, donor site morbidity in cases in which autologous bone graft is used may occur in as many as $25 \%$ of cases. $^{21,22}$ It is also well known that implantation of a rigid internal fixation construct without achieving fusion of the bridged segment may cause fatigue failure of the implanted system. ${ }^{8,16}$

Dynamic stabilization systems permit restricted movement across a functional spinal unit. These principles have been described by Mulholland and Sengupta, ${ }^{17}$ who believe that these systems work either by restricting movement to a zone or range at which normal or near-normal loading can occur, or by preventing the spine from adopting a position in which abnormal loading may occur. These systems also are designed to preserve the intersegmental kinematics and to reduce loading of the facet joints.

The Dynesys Spinal System (Zimmer Spine) is a nonfusion pedicle screw-based stabilization system that was developed in an attempt to overcome the inherent disad- 


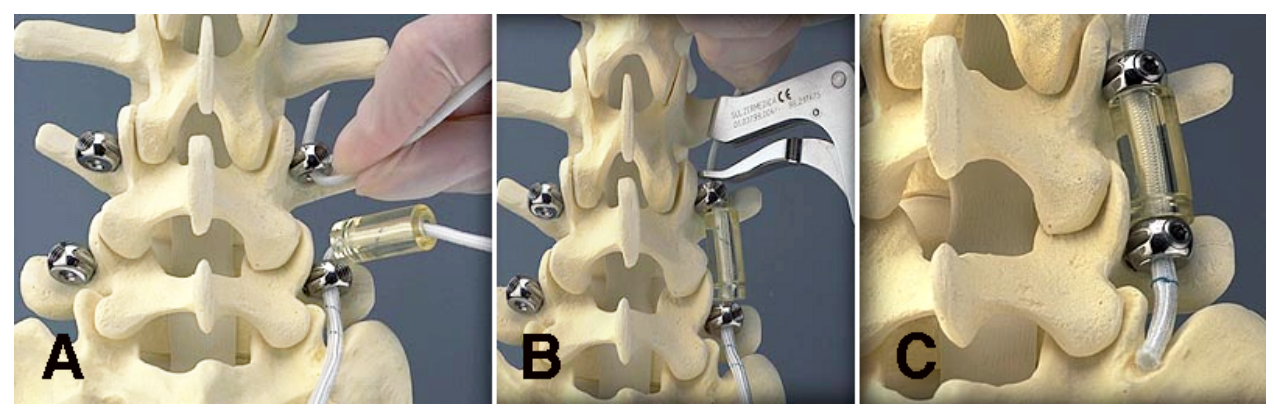

FIG. 1. Photographs of a spine model showing the various stages of implantation of the Dynesys spinal system. A: The PET cord of the Dynesys implant is inserted through the tubular spacer and into the second screw head. B: A tensioning instrument is used to exert tension on the PET cord at the other end of the segment with the specified preload. $\mathrm{C}$ : The Dynesys spinal system in its final shape and position. The pedicle screws are connected with a system of a central cord and cylindrical spacers.

vantages of rigid instrumentation and fusion. ${ }^{12}$ It was introduced in 1994 by Dubois et al. ${ }^{6}$ according to the hypothesis that segmental stabilization is possible with this implant without bone grafting. Since then, a number of studies have been completed in which the clinical outcome of patients who underwent Dynesys implantation was examined., ${ }^{2,6,12,19,24,27}$

In this report we describe the preliminary clinical results for implantation of the Dynesys spinal system in patients participating in a Food and Drug Administration IDE clinical trial. Changes in pain, function, and patient satisfaction over a 1-year follow-up period in 101 patients enrolled and randomized to be treated with the Dynesys spinal system were examined. The rate of complications and potential need for additional surgical intervention are also presented to assess the safety of the Dynesys spinal system. Our hypothesis is that the clinical results of dynamic stabilization in patients with degenerative lumbar spine disease are equivalent to those seen after instrumented lumbar fusion.

\section{Clinical Material and Methods}

\section{Device Information}

The Dynesys spinal stabilization system consists of the following components: 1) titanium alloy pedicle screws (Protasul 100) that have a textured surface, fixed head, and self-tapping threads; 2 ) tensioning cords made of PET (Sulene-PET); and 3) longitudinal tubular spacers made of polycarbonate urethane (Sulene-PCU). These components are shown in Fig. 1.

The screws anchor the Dynesys system in the pedicle and in the vertebral body and are designed to promote bone on-growth. The PET cord runs through the hollow core of the spacers and the eye of the pedicle screw. The cords stabilize the system by a tensile preload that provides uniform system rigidity. They also act against tensile forces as well as flexion moments. ${ }^{23}$ The spacers, which are cut intraoperatively to the appropriate length for the patient's anatomy, fit between the pedicle screw heads and are designed to provide resistance to compressive forces and to facilitate load transfer. Because of their elasticity, the spacers ensure a reduction in mechanical stresses on the vertebral segments.

The length of the spacer is an important parameter that directly influences both intersegmental motion and loading, because it determines the segmental position (disc height, facet joint position, and tension of the ligaments). ${ }^{18}$ The inherent stability of the whole construct also resists bending and shear forces. ${ }^{27}$

\section{Study Design}

This study was designed as a noncomparative, prospective clinical investigation. In this report we present the clinical outcomes in 101 patients (all patients from six IDE sites were included) who underwent dynamic stabilization of the lumbar spine with Dynesys.

\section{Patient Selection}

A total of 101 patients from six IDE sites who had undergone dynamic stabilization of the lumbar spine with the Dynesys system between March 2003 and May 2006 were included in this study. Of these, 53 were women and 48 were men, and their mean age was 56.3 years (range 27-79 years). The mean BMI was 28.8 (range 24.1-30.2). A positive smoking history was recorded in 21 patients and a secondary gain issue (lawsuit or workers' compensation claim) was present in $12.87 \%$ of the study group. Forty-three prior lumbar surgeries (one or more per patient) were recorded, including 20 decompressive laminectomies and 10 percutaneous discectomies, for a mean of 0.42 prior lumbar surgeries per patient (Table 1).

On average, the patients' preoperative symptoms had lasted for 5.3 years (range $0.2-36.9$ years). The mean preoperative pain intensity, as documented in the clinical evaluation with $100-\mathrm{mm}$ VAS, was 80.3 for leg pain (range 14-100) and 54 for back pain (range 1-98). The mean ODI score of the study group was 55.6\% (range 28-90\%).

The primary indication for surgery was spondylolisthesis in 20 patients and central canal stenosis in 26. Table 2 shows the primary indication for surgery in the study group (one indication per patient) and also all indications for surgery (one or more per patient).

Inclusion criteria required all patients to have degenerative spondylolisthesis or retrolisthesis (up to Grade I), to have lateral or central spinal stenosis as diagnosed on neuroimaging studies, and to qualify for posterior lumbar spinal decompression and instrumented fusion for a singlelevel or contiguous two-level disease between L-1 and 
TABLE 1

Preoperative data in 101 patients who underwent dynamic stabilization

\begin{tabular}{ll}
\hline \multicolumn{1}{c}{ Factor } & \multicolumn{1}{c}{ Value (\%) } \\
\hline no. of patients enrolled & 101 \\
sex & \\
male & $48(47.5)$ \\
female & $53(52.5)$ \\
age in yrs & 56.3 \\
range & $27-79$ \\
BMI & 28.8 \\
range & $24.1-30.2$ \\
positive smoking history & 21 of $101(20.8)$ \\
secondary gain issue* & 13 of $101(12.87)$ \\
prior lumbar ops & 43 \\
percutaneous discectomy & 10 \\
decompressive laminectomy & 20 \\
fusion & 9 \\
other & 4
\end{tabular}

* Lawsuit or workers' compensation claim.

S-1. Patients had a predominant component of leg pain (a preoperative score $\geq 40 \mathrm{~mm}$ on a $100-\mathrm{mm}$ VAS) rather than back pain symptoms. Enrolled patients had at least moderate disability (a preoperative ODI of $\geq 30 \%$ ) and were unresponsive to conservative management for a minimum of 3 months.

Exclusion criteria ruled out patients who had undergone a previous lumbar fusion attempt, previous total facetectomy, or trauma at the affected level. Patients with diseases that preclude surgical management (severe osteoporosis, osteopenia, immune suppression, malignancy, and active local and/or systemic infection) were excluded from the study. Patients younger than 20 years or older than 80 years of age or those with morbid obesity as measured by a BMI greater than 40 also were excluded.

\section{Preoperative Assessment}

The preoperative evaluation included patient history, physical examination, neurological examination, and the assessment of imaging studies. Imaging included anteroposterior, lateral, and dynamic lateral x-ray films, and in most cases computed tomography and magnetic resonance imaging of the lumbosacral spine. The ODI questionnaire according to Fairbank was used to assess subjective functional impairment. ${ }^{10}$ This questionnaire rates the following 10 parameters: pain intensity, personal care, lifting, walking, sitting, standing, sleeping, sex life, social

TABLE 2

Indication for surgery in 101 patients who underwent dynamic stabilization

\begin{tabular}{lcc}
\hline \hline \multicolumn{1}{c}{ Indication } & $\begin{array}{c}\text { As Primary Indication } \\
\text { for Op (1/patient })^{*}\end{array}$ & $\begin{array}{c}\text { All Indications } \\
(\geq 1 / \text { patient })\end{array}$ \\
\hline spondylolisthesis & 20 & 52 \\
retrolisthesis & 3 & 10 \\
central stenosis & 26 & 58 \\
lat stenosis & 40 & 63 \\
other & 4 & 34 \\
\hline
\end{tabular}

* Eight patients had incomplete records. life, and traveling. Additionally, the pain was quantified using a 100-mm VAS for both leg and axial low-back pain. $^{3}$ The General Health Measures (SF-12; MCS and PCS Scores) were also assessed preoperatively. ${ }^{13}$

\section{Surgical Procedure}

The Dynesys construct was implanted using standard surgical procedures for posterior lumbar spinal surgery. After a midline incision and subperiosteal retraction of the paraspinal muscles, the affected segment was exposed. Decompression was performed as necessary, with preservation of the discs and facet joints whenever possible. After adequate decompression, the titanium alloy pedicle screws were inserted, and their correct positions were confirmed using anteroposterior and lateral fluoroscopy. The interpedicular spacers were cut to size and the cord and spacer construct was positioned between two pedicle screws. The PET cord was secured at one end of the segment by tightening the setscrew in the head of the pedicle screw (Fig. 1A). A tensioning instrument was used to exert tension on the PET cord at the other end of the segment with the specified preload, and the remaining setscrew was tightened (Fig. 1B). No further distraction or lordosis was applied to the segment, and no attempt to reduce the translational instability was made (Fig. 1C). The wound was closed in a standard fashion. Patients were allowed to get up on the 1st postoperative day.

\section{Perioperative Data}

The duration of surgery, blood loss during surgery, and the duration of inpatient treatment were recorded. Intraoperative and perioperative major and minor complications were assessed.

\section{Clinical Follow-Up Evaluation}

The patients returned for follow-up evaluations at 3 weeks and at 3,6, and 12 months after surgery. During the follow-up visit the following data were collected: location of pain; intensity of leg and back pain according to the 100-mm VAS; neurological symptoms; pain medication; complications caused by the operation; subsequent spinal surgery; and assessment of the patient's functional impairment according to the ODI. The General Health Measures scores (SF-12; MCS and PCS) were also assessed in each of the follow-up visits. The patient's perception of the operation in the form of his or her satisfaction and willingness to recommend the operation to a friend or relative who had the same condition was evaluated on the 100-mm VAS for both items. ${ }^{5}$

\section{Results}

\section{Perioperative Data}

The mean duration of surgery was 184 minutes (range 75-340 minutes) and the mean blood loss was $451 \mathrm{ml}$ (range 75-1750 ml). A one-level construct was implanted in $56 \%$ of the patients and $44 \%$ were treated with a twolevel construct. Figure 2 shows the distribution of the treated levels based on the level of the construct within the study group. The patients' mean hospital stay was 3.4 days (range $2-13$ days). 


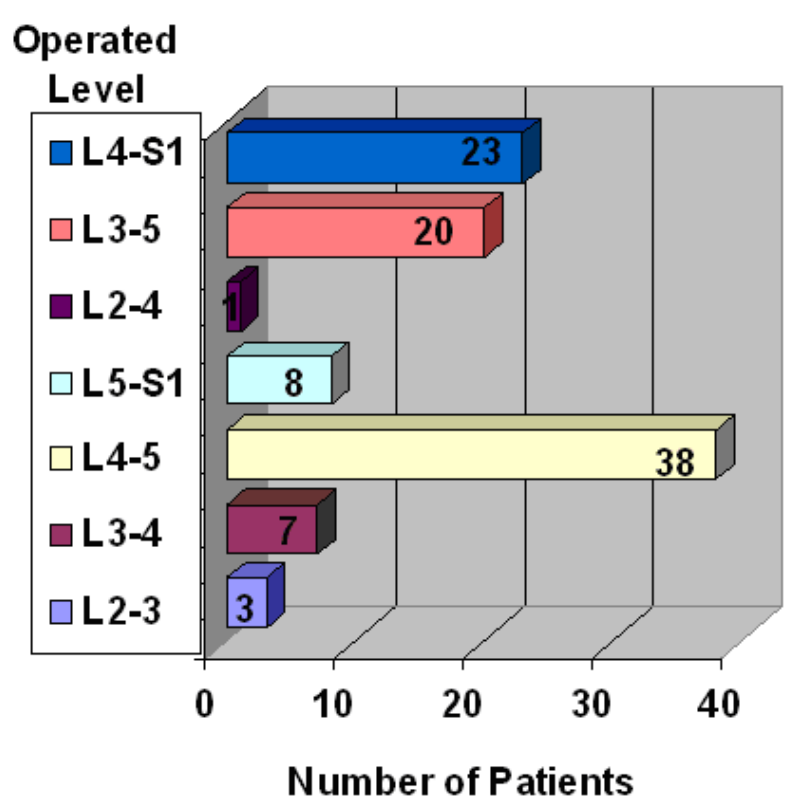

FIG. 2. Bar graph showing distribution of the level of the construct within the study group.

\section{Clinical Outcome}

The clinical outcomes at the 3-week, 3-month, and 6month follow-up visits are presented for the mean of the whole study group. The clinical outcome of the 1-year follow-up visit is presented for the mean of only the first 80 patients $(80 \%)$ who reached the 1-year follow up point. As shown in Fig. 3, at the 1-year follow-up evaluation, the

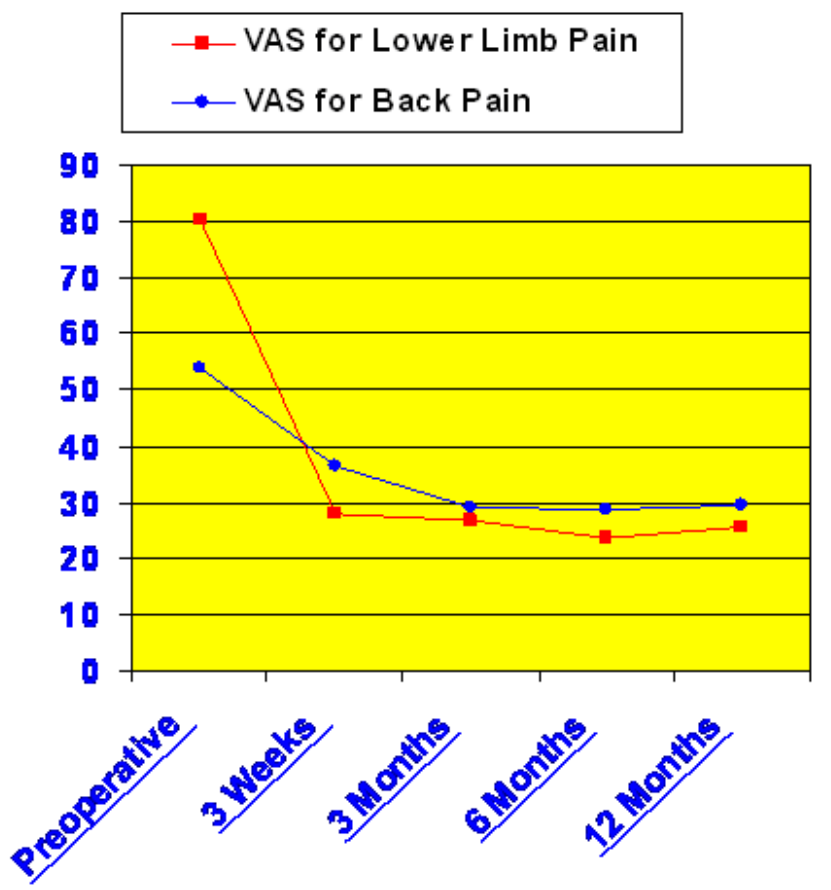

FIG. 3. Chart showing significant decrease in the pain intensity on VAS for both lower-limb and back pain over the 1-year followup period. mean lower-limb pain according to the 100-mm VAS decreased significantly, to 25.5 (range 0-96; $p<0.01$ ), and the mean back pain based on the VAS also decreased significantly, to 29.4 (range $0-95 ; \mathrm{p}<0.01$ ).

Patient functional impairment as measured by the mean ODI score also showed significant improvement over the course of the follow-up period (Fig. 4). The ODI is scored on a scale of 0 to $100 \%$, where 0 to $20 \%$ means minimal disability, 20 to $40 \%$ means moderate disability, 40 to $60 \%$ means severe disability, 60 to $80 \%$ means crippled, and 80 to $100 \%$ means either bedridden or exaggerating symptoms..$^{10}$ The preoperative mean ODI score was $55.6 \%$ (range 28-90\%), which denoted a severe disability for the average patient. At the 12-month follow-up visit the mean score was $26.3 \%$ (range $0-94 \%$ ), which indicated a moderate disability only for the average patient. This improvement was also statistically significant $(\mathrm{p}<0.01)$.

At the time of follow-up evaluation, the patients' General Health Measures (SF-12) score showed significant improvement. The mean SF-12 MCS score of the study Group Improved significantly, from 41.6 preoperatively to 49.4 at the 12-month follow-up visit ( $<<0.01$ ). Also, the mean SF-12 PCS score of the study group has improved significantly, from 27.3 preoperatively to 40.3 at the 12-month follow-up visit $(\mathrm{p}<0.01)$.

At the 12-month follow-up visit, the mean patient satisfaction as evaluated with the 100-mm VAS was 79, and the mean of the patients' willingness to recommend the operation to a friend or relative with the same condition as evaluated with the 100-mm VAS was 73.1.

Statistical analysis of the patients' variables revealed no significant difference in the parameters of the clinical outcome between the group of patients who were treated with Dynesys for one-level and those who were treated for twolevel disease. Also, there was no significant difference between the smokers and nonsmokers. The presence of secondary gain issues significantly affected the clinical outcome, with poor improvement in scores for ODI, 100-

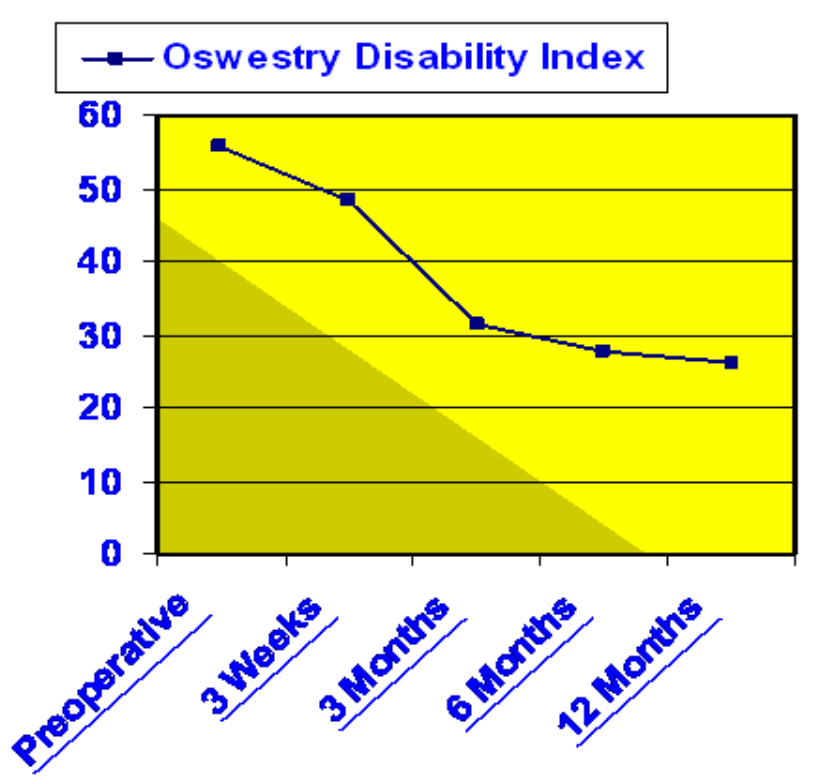

FIG. 4. Chart showing significant, gradual decline in the mean ODI score of the study group over the 1-year follow-up period. 

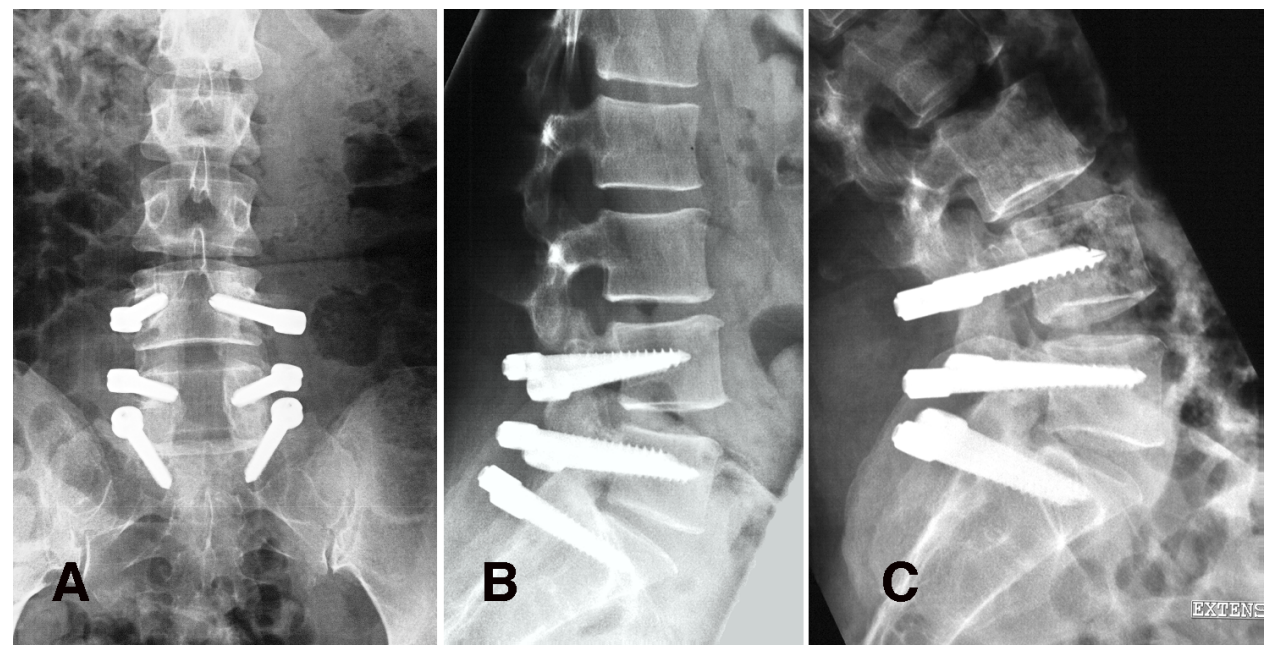

FIG. 5. Anteroposterior (A), lateral erect (B), and lateral extension (C) x-ray films obtained in a 48-year-old woman at her 2-year follow-up visit. In radiographs obtained in patients with Dynesys constructs, only the pedicle screws are visible.

mm VAS for lower-limb and back pain, and the General Health Measures SF-12.

\section{Complications Within the Study Group and Additional Surgery}

There were 16 intraoperative complications reported (15.8\%): 12 of these were dural tears, 11 of which were discovered and repaired intraoperatively. One dural tear was diagnosed immediately postoperatively and was resolved with bed rest. One of these dural tears continued to leak and an additional surgical procedure was required to close the lesion again. There were two instances of excessive blood loss requiring transfusion. One patient suffered an allergic reaction to anesthesia; the procedure was aborted and rescheduled. The remaining intraoperative complication was a fractured pedicle, which occurred during screw insertion. The pedicle screw was not placed and a hemilaminectomy was completed.

Fifteen $(15 \%)$ of 101 patients required 18 reinterventions by the time of the 1-year follow-up evaluation. Eleven of the patients $(11 \%)$ underwent 13 procedures related to the spine or to the index surgery. Five procedures needed by four patients (4\%) were unrelated to the spine or the initial surgery.

Three of these 18 procedures were necessitated by immediate postoperative complications. One patient experienced postoperative respiratory arrest and required tracheostomy. One patient experienced a wound dehiscence and was treated with debridement. The third patient presented with cerebrospinal fluid leakage due to a dural tear and required suturing and sealing of the tear with fibrinogenic material.

Ten of the 18 reinterventions were revision surgery performed at the same spinal level due to radiculopathy, increased back pain, or increased instability, and these surgeries included decompression, extension of the segmental fixation, or removal of extradural synovial facet cyst as needed in each case. In three of these 10 reinterventions, removal of the stabilization system was required. One patient suffered radicular symptoms and required decom- pression and Dynesys explantation, and in one patient back pain developed, with screw loosening noted at operation. The third patient underwent removal of the Dynesys construct because of radicular symptoms that required laminectomy and pedicle resection. The other five of the 18 reinterventions were not related to the spine and included two total hip replacements, tendon release for hammer toe deformity, toe implant removal, and aspiration of knee effusion.

\section{Discussion}

In a computerized search conducted by Resnick et al., ${ }^{20}$ the database of the National Library of Medicine was queried for articles published between 1966 and 2003 in which the terms "lumbar spine fusion assessment," "lumbar spine pseudarthrosis," or "lumbar spine fusion outcome" were used. The authors concluded that the correlation between the fusion status and the clinical outcome is not strong, and that in a given patient, fusion status may be unrelated to clinical outcome. In accordance with the findings of Resnick et al., we propose that solid fusion may not be the standard treatment for DDD. New interventions and clinical trials of equipment developed to improve the clinical outcome of patients with degenerative spine diseases are still needed.

Our 1-year preliminary clinical results after application of the Dynesys spine system show the ability of this dorsally implanted system to improve clinical outcome and to decrease the patient's disability and pain. This is reflected in the significant improvement of the mean pain and function scores from baseline to the 12-month follow-up visit, as follows: based on the 100-mm VAS score, leg pain improved from 80.3 to 25.5 ; back pain improved from 54 to 29.4; and the ODI score improved from 55.6 to $26.3 \%$. This is analogous to a 68.2 and $45.5 \%$ improvement in the score for the lower-limb and back pain, respectively, and a 52.7\% improvement in the ODI. Examples of our cases are presented in Figs. 5 and 6. Patients treated with dynamic stabilization also showed significant improvement in the General Health Measures (SF-12) score, and gener- 

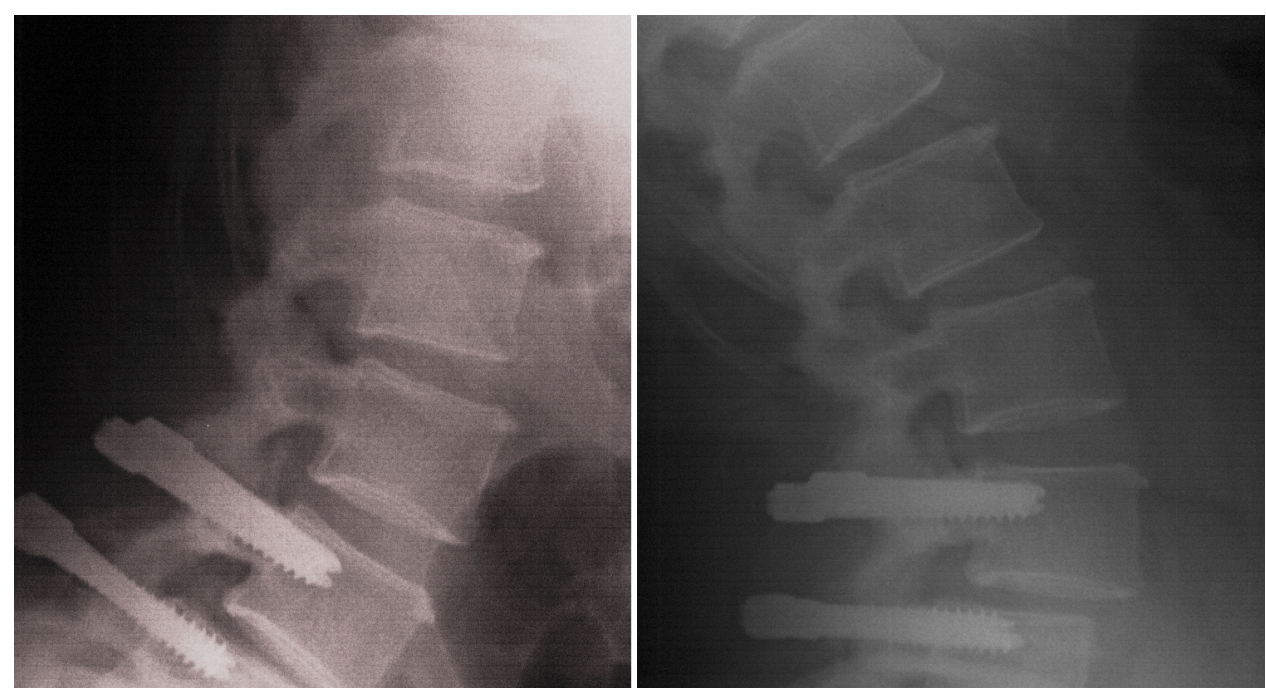

FIG. 6. Postoperative radiographs in flexion (left) and extension (right) views demonstrating maintenance of sagittal alignment at the 1-year follow-up visit in a 51-year-old woman with degenerative spondylolisthesis at L4/5.

ally expressed high satisfaction and willingness to undergo the operation again under the same conditions.

The results of a literature review of the clinical studies performed to determine the outcomes after treatment with the Dynesys spinal system are presented in Table 3. The results of our study correlate well with most of these, in which similar measures of the clinical outcome were used. The results reported by Schnake et al., ${ }^{24}$ Bordes-Monmeneu et al., ${ }^{2}$ Stoll et al., ${ }^{27}$ and Dubois et al. ${ }^{6}$ show the significant reduction in pain and disability scores in groups of patients who have similar indications for surgery compared with those in our study. The results reported by Grob et al. ${ }^{12}$ show moderate improvement of the clinical outcome, but it was noticed in that study that less satisfactory outcomes may have been related to lack of surgical decompression in some of the patients in whom the Dynesys construct had been implanted. In other studies investigators have also suggested that clinical outcomes are less satisfactory in patients who received dynamic implants without decompression. ${ }^{12,24,27}$ We can conclude that the early clinical outcome in patients undergoing surgery for degenerative spinal diseases, either for fusion or for dynamic stabilization, depends on the efficacy of decompression, and that the long-term clinical outcome is still a matter for debate and requires a randomized controlled study with long-term follow up.

The accepted level of complications in our series may relate to the fact that Dynesys is less invasive compared with most posterior fusion procedures. There is no need for graft site preparation with resulting posterolateral extension of the soft tissue damage, and no harvest site morbidity. The mean operating time for Dynesys implantation is shorter in our study (184 minutes) compared with other fusion procedures. One of the advantages of the Dynesys system that may decrease the rate of complications is that it allows the treatment of degenerative lumbar disease in a segment-by-segment manner. This means that with multisegmental degeneration, the stabilizing procedure can be restricted to one segment above or below a degenerated but stable segment-a decision that would not be consid- ered with fusion, resulting in the extremely invasive and probably unnecessary extensions of fusions that are frequently observed. ${ }^{27}$

The Dynesys system appears to restabilize the spinal segments without requiring fusion across the intervertebral discs or the facet joints. The stabilized segments appear to retain some mobility, which may help to reduce pain. Dynesys implantation with preservation of the disc and the facets may create a favorable environment in the motion segment by unloading these joints and permitting more normal motion. ${ }^{25}$ The resumption of mobility in the moderately degenerated disc and facet joint also may slow the degenerative spinal process..$^{19,25}$

The clinical outcome of dynamic stabilization with Dynesys is comparable to that reported in the literature regarding fusion. This system allows stabilization of the spine with preservation of its dynamic nature and eliminates the bone graft harvest with its associated morbidity. However, a long-term follow-up duration is crucial to support a recommendation of dynamic stabilization as the ideal method for treating degenerative spine diseases.

\section{Conclusions}

First, the early results attained with the Dynesys implants are promising. Patients treated with dynamic stabilization reported less pain and lower disability scores at 3 weeks and at 3,6, and 12 months. Second, dynamic stabilization may be preferable to fusion for surgical treatment of degenerative spondylolisthesis and stenosis because it decreases back and leg pain while avoiding the donor site problems and morbidity encountered in fusion, and it maintains the stability of the lumbar spine without eliminating its motion. Third, long-term follow-up studies are crucial to support the recommendation of dynamic stabilization as the ideal method for treating degenerative spine diseases.

\section{Disclosure}

Mr. Macenski is an employee of Zimmer Spine, Minneapolis, 


\section{Clinical outcomes of the Dynesys dynamic neutralization system}

TABLE 3

Review of the literature for studies investigating the clinical outcome after use of the Dynesys spinal system

\begin{tabular}{|c|c|c|c|c|c|}
\hline $\begin{array}{l}\text { Authors } \\
\& \text { Year }\end{array}$ & $\begin{array}{l}\text { No. of } \\
\text { Patients }\end{array}$ & $\begin{array}{l}\text { Indication } \\
\text { for Op }\end{array}$ & Op Procedure & $\begin{array}{c}\text { Mean } \\
\text { FU }\end{array}$ & Clinical Outcome \\
\hline $\begin{array}{l}\text { Schnake } \\
\text { et al., } 2006\end{array}$ & 26 & $\begin{array}{l}\text { lumbar stenosis, } \\
\text { degenerative } \\
\text { spondylolisthesis }\end{array}$ & decompression + Dynesys & $2 \mathrm{yrs}$ & $\begin{array}{l}\text { 100-mm VAS score for leg pain } \\
\text { improved from } 80 \text { to 23; increased } \\
\text { walking distance (this improvement is } \\
\text { statistically significant); }{ }^{*} \\
\text { patients show marked satisfaction w/ } \\
\text { the op \& } 87.5 \% \text { would do it again } \\
\text { under the same conditions }\end{array}$ \\
\hline $\begin{array}{l}\text { Bordes- } \\
\text { Monmeneu } \\
\text { et al., } 2005\end{array}$ & 94 & $\begin{array}{l}\text { lumbar stenosis, } \\
\text { DDD, disc herniation }\end{array}$ & decompression + Dynesys & & $\begin{array}{l}\text { 100-mm VAS score for leg pain } \\
\text { improved from } 80 \text { to 23; increased } \\
\text { walking distance (this improvement is } \\
\text { statistically significant); } * \\
\text { patients show marked satisfaction w/ } \\
\text { the op \& } 87.5 \% \text { would do it again } \\
\text { under the same conditions }\end{array}$ \\
\hline $\begin{array}{l}\text { Grob et al., } \\
2005\end{array}$ & 31 & $\begin{array}{l}\text { degenerative disease } \\
\text { (disc/stenosis) w/ } \\
\text { associated instability }\end{array}$ & $\begin{array}{l}\text { decompression + Dynesys } \\
\text { in 13; Dynesys alone in } 18\end{array}$ & $2 \mathrm{yrs}$ & $\begin{array}{l}67 \& 64 \% \text { improved VAS for back \& } \\
\text { leg symptoms, respectively; } * \\
50 \% \text { of patients said the op had } \\
\text { helped \& improved their overall } \\
\text { quality of life }\end{array}$ \\
\hline $\begin{array}{l}\text { Putzier et al., } \\
2005\end{array}$ & $35 \dagger$ & disc prolapse & nucleotomy + Dynesys & $34 \mathrm{mos}$ & $\begin{array}{l}\text { significant improvement of VAS score } \\
\text { for back \& lower-limb pain } \\
\& \text { in the ODI }\end{array}$ \\
\hline $\begin{array}{l}\text { Stoll et al., } \\
2002\end{array}$ & 83 & $\begin{array}{l}\text { unstable segmental } \\
\text { condition (lumbar } \\
\text { stenosis, degenerative } \\
\text { spondylolisthesis, DDD) }\end{array}$ & decompression + Dynesys & $38.1 \mathrm{mos}$ & $\begin{array}{l}\text { VAS for back pain improved from } 7.4 \\
\text { to } 3.1 \text {; VAS for leg pain improved } \\
\text { from } 6.9 \text { to } 2.4 \text {; ODI improved from } \\
55.4 \text { to } 22.9 \text { (this improvement is } \\
\text { statistically significant)* }\end{array}$ \\
\hline $\begin{array}{l}\text { Dubois } \\
\text { et al., } 1999\end{array}$ & 57 & DDD & decompression + Dynesys & $13 \mathrm{mos}$ & $\begin{array}{l}\text { pain assessed using a 4-point score, \& } \\
\text { activity level assessed based on the } \\
\text { MacNab scale; 63\% free of pain \& } \\
30 \% \text { w/ mild pain; } 85 \% \text { had excellent } \\
\text { or good results (MacNab score) }\end{array}$ \\
\hline
\end{tabular}

* Results for Dynesys + decompression were far better than for Dynesys alone.

$\dagger$ Comparative study with 84 patients who underwent nucleotomy alone.

Minnesota. Drs. Welch, Davis, Maxwell, Delamarter, Wingate, and Sherman are consultants for the company, and Mr. Cheng and Dr. Awad have no financial interest in Zimmer.

\section{Acknowledgment}

We thank Pat Karausky, R.N., B.S.N., C.C.R.C., for her help.

\section{References [au: \#7 not cited; please cite in text]}

1. Boos N, Webb JK: Pedicle screw fixation in spinal disorders: a European view. Eur Spine J 6:2-18, 1997

2. Bordes-Monmeneu M, Bordes-García V, Rodrigo-Baeza F: Sáez D: [System of dynamic neutralization in the lumbar spine: experience on 94 cases.] Neurocirugía (Astur) 16:499-506, 2005 (Spanish)

3. Chapman CR, Casey KL, Dubner R, Foley KM, Gracely RH, Reading AE: Pain measurement: an overview. Pain 22:1-31, 1985

4. Chou WY, Hsu CJ, Chang WN, Wong CY: Adjacent segment degeneration after lumbar spinal posterolateral fusion with instrumentation in elderly patients. Arch Orthop Trauma Surg 122:39-43, 2002

5. Daltroy LH, Cats-Baril WL, Katz JN, Fossel AH, Liang MH: The North American spine society lumbar spine outcome assessment instrument: reliability and validity tests. Spine 21: 741-749, 1996

6. Dubois B, de Germay B, Schaerer NS, Fennema P: Dynamic neutralization: A new concept for restabilization of the spine, in Szpalski M, Gunzburg R, Pope MH, (ed): Lumbar Segmental Instability. Philadelphia: Lippincott Williams \& Wilkins, 1999, pp 233-240

7. Eberlein R, Holzapfel GA, Schulze-Bauer C: Assessment of a spinal implant by means of advanced FE modeling of intact human intervertebral discs, in Mang HA, Rammerstorfer FG, Eberhardsteiner J (eds): Proceedings of the Fifth World Congress on Computational Mechanics, July 7-12, 2002, Vienna, Austria. Vienna, Austria: International Association for Computational Mechanics, 2002, pp 1-14

8. Esses SI, Sachs BL, Dreyzin V: Complications associated with the technique of pedicle screw fixation. A selected survey of ABS members. Spine 18:2231-2239, 1993

9. Etebar S, Cahill DW: Risk factors for adjacent-segment failure following lumbar fixation with rigid instrumentation for degenerative instability. J Neurosurg 90 (2 Suppl):163-169, 1999

10. Fairbank JCT, Couper J, Davies JB, O'Brien JP: The Oswestry low back pain disability questionnaire. Physiotherapy 66: 271-273, 1980

11. Gibson JN, Grant IC, Waddell G: The Cochrane review of surgery for lumbar disc prolapse and degenerative lumbar spondylosis. Spine 24:1820-1832, 1999

12. Grob D, Benini A, Junge A, Mannion AF: Clinical experience with the Dynesys semirigid fixation system for the lumbar spine surgical and patient-oriented outcome in 50 cases after an average of 2 years. Spine 30:324-331, 2005 
13. Jenkinson $C$, Layte R, Jenkinson D, Lawrence K, Petersen S, Paice C, et al: A shorter form health survey: Can the SF-12 replicate results from the SF-36 in longitudinal studies? J Public Health Med 19:179-186, 1997

14. Kumar MN, Baklanov A, Chopin D: Correlation between sagittal plane changes and adjacent segment degeneration following lumbar spine fusion. Eur Spine J 10:314-319, 2001

15. Markwalder TM, Wenger M: Adjacent-segment morbidity. J Neurosurg 96 (2 Suppl):139-140, 2002

16. McAfee PC, Weiland DJ, Carlow JJ: Survivorship analysis of pedicle spinal instrumentation. Spine 16 (8 Suppl): S422S427, 1991

17. Mulholland RC, Sengupta DK: Rationale, principles and experimental evaluation of the concept of soft stabilization. Eur Spine J 11 (2 Suppl): S198-S205, 2002

18. Niosi CA, Zhu QA, Wilson DC, Keynan O, Wilson DR, Oxland TR: Biomechanical characterization of the three-dimensional kinematic behavior of the Dynesys dynamic stabilization system: an in vitro study. Eur Spine J 15:913-922, 2006

19. Putzier M, Schneider SV, Funk JF, Tohtz SW, Perka C: The surgical treatment of the lumbar disc prolapse nucleotomy with additional transpedicular dynamic stabilization versus nucleotomy alone. Spine 30: E109-E114, 2005

20. Resnick DK, Choudhri TF, Dailey AT, Groff MW, Khoo L, Matz PG, et al: Guidelines for the performance of fusion procedures for degenerative disease of the lumbar spine. Part 5: correlation between radiographic and functional outcome. J Neurosurg Spine 2:658-661, 2005

21. Sawin PD: Biology of bone grafting and healing in spinal surgery, in Winn HR (ed): Youmans Neurological Surgery, ed 5. Philadelphia: WB Saunders, 2003, pp 4613-4620
22. Sawin PD, Traynelis VC, Menezes AH: A comparative analysis of fusion rates and donor-site morbidity for autogeneic rib and iliac crest bone grafts in posterior cervical fusions. J Neurosurg 88:255-265, 1998

23. Schmoelz W, Huber JF, Nydegger T, Dipl-Ing, Claes L, Wilke HJ: Dynamic stabilization of the lumbar spine and its effect on adjacent segments: an in vitro experiment. J Spinal Disord Tech 16:418-423, 2003

24. Schnake KJ, Schaeren S, Jeanneret B: Dynamic stabilization in addition to decompression for lumbar spinal stenosis with degenerative spondylolisthesis. Spine 31:442-449, 2006

25. Sengupta DK: Dynamic stabilization devices in the treatment of low back pain. Neurol India 53:466-474, 2005

26. Sengupta DK, Mulholland RC: Fulcrum assisted soft stabilization system: a new concept in the surgical treatment of degenerative low back pain. Spine 30:1019-1030, 2005

27. Stoll TM, Dubois G, Schwarzenbach O: The dynamic neutralization system for the spine: a multi-center study of a novel non-fusion system. Eur Spine J 11 (Suppl 2): S170-S178, 2002

Manuscript submitted October 12, 2006.

Accepted November 20, 2006.

Address reprint requests to: Address reprint requests to: William C. Welch, M.D., Department of Neurological Surgery, University of Pennsylvania Medical Center-Health System, Presbyterian University Hospital, Suite B-400, 200 Lothrop Street, Pittsburgh, Pennsylvania 15213-2582. email: Welchwc@upmc.edu. 